Novas eleições, novas estratégias? O HGPE dos candidatos à prefeitura de

Curitiba em 2012 e 2016 


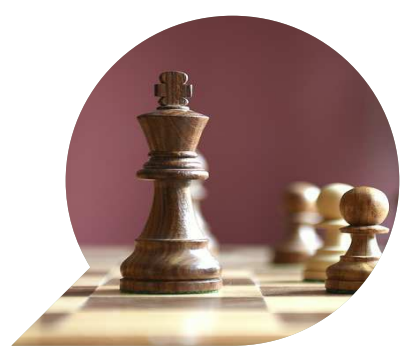

\title{
Novas eleições, novas estratégias? 0 HGPE dos candidatos à prefeitura de Curitiba em 2012 e 2016
}

\author{
New elections, new strategies? \\ Television campaign of mayor candidates in Curitiba in \\ 2012 and 2016
}

PAULO FERRACIOLI ${ }^{1}$

GIULIA SBARAINI FONTES ${ }^{2}$

Resumo: $\bigcirc$ objetivo do artigo é verificar como os candidatos à prefeitura de Curitiba Rafael Greca e Gustavo Fruet fizeram uso da propaganda eleitoral no primeiro turno da campanha de 2016, em comparação com o pleito anterior. Com esse intuito, foram utilizados dados codificados por meio da Análise de Conteúdo a partir dos programas de televisão do Horário Gratuito de Propaganda Eleitoral (HGPE). Três hipóteses são testadas: 1) a de que o candidato à reeleição Fruet passou a utilizar predominantemente as estratégias de mandatário em 2016; 2) a de que Greca não fez grandes mudanças por continuar sendo desafiante e; 3) a de que

\footnotetext{
1 Paulo Ferracioli é doutorando em Ciência Política pela Universidade Federal do Paraná (UFPR). Mestre em Comunicação pela mesma instituição. Membro do Grupo de Pesquisa em Comunicação, Política e Tecnologia (PONTE), da UFPR. Bolsista Capes. ferracioli.paulo@gmail.com.

2 Doutoranda em Ciência Política pela Universidade Federal do Paraná (UFPR). Mestre em Ciência Política e graduada em Comunicação Social - Jornalismo pela mesma instituição. Membro do Grupo de Pesquisa em Comunicação, Política e Tecnologia (PONTE). Repórter de política do jornal Gazeta do Povo. giuliasfontes@gmail.com.
} 
o tema econômico apareceria com mais frequência em 2016. Os resultados, entretanto, apontaram para a confirmação parcial da H1 - já que, para algumas variáveis típicas de mandatário, Fruet apresentou queda entre uma eleição e outra - e para a não confirmação da H2 - já que Greca apresentou mudanças na sua estratégia - e da H3 - já que a variável econômica apareceu de forma tímida em 2016, e somente na campanha de Fruet.

Palavra-chave: HGPE. Eleições majoritárias. Prefeitura de Curitiba.

\begin{abstract}
The objective of this article is to verify how two candidates to the city hall of Curitiba, Rafael Greca (PMN) and Gustavo Fruet (PDT), used their electoral propaganda in the first round of the 2016 campaign in comparison with the previous litigation. To this intent, the data were codified through content analysis from Free Political Advertising Time TV programs. Three hypotheses are tested: 1) that Fruet, the candidate for re-election, started using agent strategies in 2016; 2) that Greca did not make great changes by continuing to be defiant and; 3) that the economic issue would appear more frequently in the most recent election. The results, however, pointed to the partial confirmation of $\mathrm{H} 1$ - since, for some typical agent variables, Fruet presented a decrease between one election and the other - and for the non-confirmation of $\mathrm{H} 2$ - since Greca presented significant changes in his strategy - and H3 - as the economic variable appeared in a slight manner in 2016, and only in Fruet's campaign.
\end{abstract}

Keywords: Free Political Advertising Time. Majoritarian elections. Curitiba's city hall.

\title{
Introdução
}

O campo de pesquisa sobre o Horário Gratuito de Propaganda Eleitoral (HGPE) é um nicho que desfruta de bastante consistência no campo da comunicação política. Ao menos desde o final dos anos 1980, há várias investigações que buscam esclarecer aspectos 
sobre esse formato específico de propaganda política. Parece ser interessante, nesse sentido, continuar as discussões relacionando esse embasamento prévio às eleições municipais ocorridas ano passado.

As eleições de 2016 contaram com novas normas em decorrência da aprovação de uma minirreforma eleitoral no ano anterior (Lei n. ${ }^{\circ}$ 13.165/2015). Além disso, é necessário considerar que o país passava por turbulência econômica e política. Por um lado havia recessão nacional, com repercussões no cotidiano da população e na saúde financeira dos municípios ,e por outro outro, o país havia passado pelo impeachment da presidente Dilma Rousseff e as constantes novidades da Operação Lava Jato.

Levando em conta esse contexto mais amplo e olhando de perto o cenário eleitoral em Curitiba (PR), esse artigo tem o objetivo de verificar como os candidatos à prefeitura de Curitiba Rafael Greca e Gustavo Fruet fizeram uso da propaganda eleitoral no primeiro turno da campanha de 2016 em comparação com o pleito anterior. A opção foi realizar um estudo comparativo entre esses dois pleiteantes e entre as duas eleições municipais da década de 2010. Trata-se, nesse sentido, de buscar observar se, empiricamente, se confirmam as premissas teóricas a respeito do comportamento de candidatos mandatários (caso de Fruet em 2016) e desafiantes (personalizado no artigo por Rafael Greca, que não buscava a reeleição em nenhum dos pleitos) durante campanhas eleitorais.

Para tanto, testamos três hipóteses neste artigo. A primeira é de que Fruet passou, em 2016, a utilizar de maneira predominante as estratégias típicas de mandatário em detrimento das de desafiante, justamente por ser candidato à reeleição. A segunda é de que, no caso de Greca, poucas foram as mudanças já que em ambos os pleitos ele foi o candidato desafiante. A terceira diz respeito aos temas abordados nos programas de HGPE, que mudam de acordo com o ambiente político em cada eleição. Espera-se, dessa forma, que em 2016 questões econômicas apareçam com mais frequência nos programas dos candidatos, devido ao momento de crise vivido pelo país, em detrimento dos temas que predominaram na primeira eleição da década.

Em relação à estrutura, esse trabalho começa com uma contextualização sobre os dois pleitos que forneceram o material empírico para a análise. Em seguida, apresenta-se uma revisão da 
literatura pertinente à pesquisa aqui desenvolvida. A seguinte seção apresenta os procedimentos metodológicos e os resultados alcançados. Por fim, há a discussão dos achados da pesquisa e as considerações finais cabíveis.

\section{As eleições majoritárias em Curitiba}

As eleições de 2012 contaram com sete candidatos autorizados a disputar a prefeitura do município. No primeiro turno, a surpresa foi a terceira colocação do candidato apoiado pelo governo do Estado Luciano Ducci (Partido Socialista Brasileiro - PSB), que concorria à reeleição. Ele alcançou apenas 261.049 dos votos e não pôde disputar o segundo turno do pleito mencionado.

No primeiro turno dessa eleição, que será analisado nesse artigo, o candidato Gustavo Fruet, que viria a ser vitorioso no segundo turno e comandaria a capital entre 2013 e 2016, chegou na segunda posição, com 265.451 votos válidos (27,22\%). O então candidato havia disputado as eleições para senador em 2010 pelo Partido da Social Democracia Brasileira (PSDB) e ficou em terceiro lugar. Na eleição municipal ele já havia se transferido para o Partido Democrático Trabalhista (PDT), que compôs a coligação com Partido dos Trabalhadores (PT) e Partido Verde (PV), Ihe garantindo cinco minutos e cinquenta oito segundos de tempo no HGPE.

Um de seus oponentes era Rafael Greca, que já havia sido chefe do Poder Executivo local entre 1993 e 1996. Ele concorreu pelo então Partido do Movimento Democrático Brasileiro (PMDB), saindo da eleição com a quarta posição e 101.866 votos válidos (10,45\%). Disputou o cargo por uma chapa composta apenas por esse partido, o que lhe permitiu desfrutar de quatro minutos e dez segundos no HGPE, porém nunca alcançou protagonismo midiático nesse pleito. As atenções se voltaram mais para os três primeiros candidatos, que eram considerados os com

2 A título exemplificativo, na pesquisa IBOPE divulgada em 06 de outubro de 2012, Greca aparecia com 9\% das intenções de voto, contra 35\%, 26\% e 19\% dos outros concorrentes. Sondagem registrada no Tribunal Regional Eleitoral do Paraná (TRE-PR) sob o número PR- PR-00654/2012. 
maior chance de conquistar o cargo. Nas sondagens antes da votação, Greca sempre apareceu na quarta posição, nunca apresentando tendência de se aproximar dos mais votados².

Já nas eleições de 2016, esses candidatos voltaram a participar do pleito, mas a partir de posições diferentes. Rafael Greca, agora por uma legenda de menor expressão - o Partido da Mobilização Nacional (PMN) -, foi para o segundo turno na primeira posição, com 356.539 votos (38,38\% dos votos válidos). Sua coligação, no entanto, era ampla, composta por sete partidos (PMN, PSDB, PSB, Democratas - DEM, Partido Trabalhista Nacional - PTN, Partido Social Democrata Cristão - PSDC e Partido Trabalhista do Brasil - PTdoB), o que lhe garantiu o maior tempo no HGPE: 2 minutos e 11 segundos ${ }^{3}$.

Enquanto isso, Gustavo Fruet (PDT) montou uma coligação diferente, o que lhe rendeu 1 minuto e 34 segundos de tempo diário no HGPE. Ele buscava continuar no cargo, mas conquistou o apoio nas urnas de apenas 186.067 eleitores (20,03\% dos votos válidos). O resultado o deixou na terceira posição, fora da disputa do segundo turno.

O segundo turno de 2016 foi disputado por Greca, que contava com o apoio do partido do governador Beto Richa, o PSDB. O outro concorrente foi Ney Leprevost (Partido Social Democrático - PSD), que também pertencia a um partido que compunha a base de sustentação do governo estadual.

Em pesquisa divulgada logo no início do período autorizado para a campanha ${ }^{4}$, Greca liderava com 29\% das intenções, seguido por Fruet, a quem eram atribuídas 19\% das intenções de voto. Até mesmo na sondagem divulgada na véspera do dia da votação ${ }^{5}$, Fruet ainda aparecia na segunda posição, com 22\% das intenções de voto declaradas. Ney Leprevost, que aparecia com 17\% nessa pesquisa, terminou o primeiro turno com 219.727 votos $(23,66 \%$ do conjunto de válidos) , o que o levou a segundo turno por 70 mil votos a mais que o candidato a reeleição.

\footnotetext{
3 Na comparação entre os tempos de TV entre as eleições de 2012 e 2016, é preciso levar em conta que a minirreforma eleitoral de 2015 diminuiu o tempo diário dedicado ao HGPE, o que diminuiu o tempo disponível para cada candidato.

4 Pesquisa IBOPE divulgada em 23 de agosto de 2016, registrada no Tribunal Regional Eleitoral do Paraná (TRE-PR) sob o protocolo PR-04300/2016.

5 Pesquisa IBOPE divulgada em 01 de outubro de 2016, registrada no Tribunal Regional Eleitoral do Paraná (TRE-PR) sob o número PR-05284/2016.
} 
A partir da contextualização aqui apresentada, é possível perceber que Greca e Fruet ocuparam posições muito distintas nos dois pleitos. Enquanto Fruet foi de desafiante a mandatário de 2012 para 2016, Greca permaneceu desafiante, mas teve desempenho significativamente melhor na segunda eleição, chegando à Prefeitura. Por isso, o presente artigo considera apenas o uso que esses dois candidatos fizeram do HGPE, Destaca-se que a comparação desse artigo englobará apenas os dados dos candidatos Gustavo Fruet e Rafael Greca, descartando os outros políticos que pleitearam o cargo de chefe do Executivo municipal porque, a partir deles, é possível observar se as premissas da literatura a respeito das estratégias de campanha de mandatários e desafiantes se aplicam aos dois casos curitibanos. Na sequência, apresentaremos com mais pormenor o que dizem as pesquisas já consolidadas a respeito deste tema.

\section{HGPE: a propaganda televisiva eleitoral no Brasil}

As pesquisas sobre o HGPE se baseiam na premissa de que "os media se tornaram, hoje, o locus de boa parte da disputa política, bem como também um novo agente dessa disputa ao lado dos atores políticos tradicionais" (ALBUQUERQUE, 1999, p. 39). Nesse espaço mediatizado, a propaganda dos candidatos na televisão representa um meio essencial de atuação política e, por isso, tem sua relevância de análise justificada. A televisão em específico se apresenta como o meio de maior difusão entre a população brasileira.

Ainda que as pesquisas apontem que há razoável número de brasileiros que sequer assiste ao HGPE (PANKE; TESSEROLI, 2016), ele ainda permanece como um espaço privilegiado para que os candidatos possam realizar sua propaganda política durante a campanha. É um exemplo do deslocamento espacial que ocorreu com as campanhas, que saíram das ruas e passaram a predominar nas telas da televisão. $\mathrm{O}$ HGPE é, dessa maneira, de uma "forma de mediação entre candidatos e eleitores que não precisa ser encarada como uma crise do modelo anterior, mas sim como um novo modelo de campanhas políticas" (PANKE; CERVI, 2011, p. 394).

O HGPE no Brasil se desenvolveu com características próprias, que 
já foram exploradas pela literatura e que permitiram o desenvolvimento das categorias a serem utilizadas nessa análise. As mensagens articuladas em estilo 'mosaico' e as imagens de campanha são típicas do modelo, calcadas nas regras que delimitam o horário, como a apresentação de vários candidatos um após o outro, em tempos pré-determinados (ALBUQUERQUE, 1999). É impossível ignorar que a propaganda veiculada no HGPE possui um elemento lúdico, típico da televisão, que passa a disputar espaço com as questões políticas (PANKE; CERVI, 2011).

Albuquerque (1999) apresentou uma classificação do conteúdo veiculado nesses programas dividida em três grupos: campanha, metacampanha e auxiliares. O primeiro tipo engloba os trechos em que são apresentados o candidato e suas propostas. Metacampanha consiste no tipo de conteúdo que relata atos da própria campanha e busca incentivar o eleitor a participar desse processo. Por fim, as mensagem auxiliares são aquelas que conectam os temas e assemelham o programa eleitoral a um programa de televisão.

O HGPE serve, portanto, para veicular informações sobre as propostas dos candidatos ao mesmo tempo em que veicula mensagens sobre a imagem do postulante e ataca o adversário (CERVI; MASSUCHIN, 2011). Além disso, o HGPE pode atuar como fortalecimento dos partidos (ALBUQUERQUE; DIAS, 2002), ainda que a tendência seja de que as agremiações fiquem mais escondidas no HGPE, pois passa a predominar a relação mais personalista entre eleitor e candidato (PANKE; CERVI, 2011).

A delimitação dos temas trazidos pelos candidatos para seus programas não depende apenas dos temas que a população mais deseja ver resolvidos. Não há correspondência entre os temas abordados e os mais solicitados, o que indica que há outros elementos que são levados em consideração pelos candidatos para montar suas emissões (PANKE; TESSEROLI, 2015).

Pesquisas recentes têm confirmado que ao longo do período de veiculação da propaganda na televisão há alterações nas estratégias dos candidatos. O tom emocional passa a prevalecer ao decorrer do tempo, pois o apelo pragmático tende a dar espaço ao emocional conforme o dia da eleição se aproxima. Os formatos, entretanto, permanecem uniformes ao longo da candidatura - não havendo nem 
mesmo alteração entre os turnos - com a repetição de elementos típicos dessa linguagem, como a narração em off (MASSUCHIN et al., 2016).

A partir dos conceitos abordados, apresentamos, na seção seguinte, a análise realizada a respeito dos pleitos em Curitiba.

\section{Análise: os programas eleitorais de Greca e Fruet em 2012 e 2016}

Considerando a importância do HGPE como recurso durante as campanhas eleitorais, passamos à análise do objeto deste artigo. Para comparar as estratégias adotadas pelos dois candidatos nos baseamos nos estudos feitos pelo Grupo de Pesquisa em Comunicação Política e Opinião Pública (CPOP) da Universidade Federal do Paraná (UFPR), que se dedica ao estudo do Horário Gratuito de Propaganda Eleitoral desde o ano 2000.

Deste modo, a metodologia utilizada neste artigosegue o padrão adotado pelo CPOP, que faz uma Análise de Conteúdo (BAUER, 2008) quantitativa dos programas. A unidade de análise não é o programa completo, mas sim segmentos de vídeo que são determinados por três elementos: locutor, tema e cenário. Quando dois desses elementos se alteram, codifica-se um novo segmento. Tendo em vista que tanto em 2012 quanto em 2016 os dois candidatos tratados aqui não participaram do segundo turno das eleições simultaneamente, o artigo considera somente a análise feita nos programas do primeiro turno de campanha em cada pleito 6 . Sendo assim, o corpus compreende, em 2012, 163 segmentos para Fruet e 102 para Greca e, em 2016, 169 para Fruet e 186 para Greca.

Para cada segmento, os codificadores responderam a 28 variáveis descritas no livro de códigos, cuja referência é o trabalho de Figueiredo et al. (1997). As variáveis são divididas em quatro grandes grupos: estratégias discursivas, que podem ser típicas de mandatário ou de desafiante (variáveis dummy - identifica-se presença ou ausência); 
conteúdo (tema, formato, orador dominante, apelo, retórica e linguagem - todas variáveis categóricas); qualificação do conteúdo, que diz respeito à dimensão temporal abordada (passado, presente ou futuro), ao atributo destinado ao candidato ou ao adversário (pessoal, político ou administrativo) e à valência atribuída (positiva, negativa ou neutra); e, por fim, presença de elementos folk (trocadilho, bordão, rimas, poesia popular, presença de personagem da mídia, manifestações populares).

Para testar as duas hipóteses iniciais - (1) Fruet aumentou o uso de estratégias típicas de mandatário de 2012 para 2016 em detrimento das de desafiante; e (2) Greca não apresentou mudanças significativas em sua estratégia por ser desafiante nas duas eleições - recorreremos inicialmente às variáveis do grupo de estratégias discursivas, nas quais o codificador deve registrar somente presença ou ausência. A tabela 1, que segue abaixo, traz o percentual de presença das estratégias consideradas típicas de mandatário nos segmentos de cada candidato nas duas eleições em questão.

TABELA 1 - Estratégias típicas de mandatário

\begin{tabular}{|l|c|c|c|c|c|c|}
\cline { 2 - 7 } & \multicolumn{3}{|c|}{ FRUET } & \multicolumn{3}{c|}{ GRECA } \\
\cline { 2 - 7 } & $\mathbf{2 0 1 2}$ & $\mathbf{2 0 1 6}$ & Diferença & $\mathbf{2 0 1 2}$ & $\mathbf{2 0 1 6}$ & Diferença \\
\hline Uso do cargo & $4,9 \%$ & $39,1 \%$ & $34,2 \%$ & $24,5 \%$ & $18,8 \%$ & $-5,7 \%$ \\
\hline $\begin{array}{l}\text { Postura acima da } \\
\text { briga }\end{array}$ & $94,5 \%$ & $98,8 \%$ & $4,3 \%$ & $99 \%$ & $92,5 \%$ & $-6,5 \%$ \\
\hline $\begin{array}{l}\text { Associação à } \\
\text { administração } \\
\text { em disputa }\end{array}$ & $0,6 \%$ & $69,2 \%$ & $68,6 \%$ & $3,9 \%$ & $9,7 \%$ & $5,8 \%$ \\
\hline $\begin{array}{l}\text { Associação à } \\
\text { administração de } \\
\text { outra esfera }\end{array}$ & $14,1 \%$ & $2,4 \%$ & $-11,7 \%$ & $5,9 \%$ & $12,5 \%$ & $6,6 \%$ \\
\hline $\begin{array}{l}\text { Endosso de } \\
\text { lideranças } \\
\text { políticas }\end{array}$ & $8,6 \%$ & $2,4 \%$ & $-6,2 \%$ & $2 \%$ & $0,5 \%$ & $-1,5 \%$ \\
\hline $\begin{array}{l}\text { Endosso de } \\
\text { lideranças da } \\
\text { sociedade civil }\end{array}$ & $2,5 \%$ & $0 \%$ & $-2,5 \%$ & $1 \%$ & $0 \%$ & $-1 \%$ \\
\hline
\end{tabular}




\begin{tabular}{|l|c|c|c|c|c|c|}
\hline $\begin{array}{l}\text { Endosso do } \\
\text { patrono }\end{array}$ & $2,5 \%$ & $0 \%$ & $-2,5 \%$ & $1 \%$ & $0 \%$ & $-1 \%$ \\
\hline $\begin{array}{l}\text { Menção ao } \\
\text { partido/coligação }\end{array}$ & $4,3 \%$ & $0 \%$ & $-4,3 \%$ & $3,9 \%$ & $0 \%$ & $-3,9 \%$ \\
\hline
\end{tabular}

FONTE: os autores, 2018.

O que mais nos interessa, tendo em vista o objetivo de comparar os candidatos entre as campanhas, é a coluna que mostra a diferença entre 2012 e 2016. Assim, podemos perceber que Fruet não apresentou aumento do uso de todas as estratégias típicas de mandatário de uma eleição para outra. Ao contrário: das oito variáveis, cinco apresentaram queda em 2016. A que apresentou maior redução foi a associação à administração em outra esfera (que se refere a outros órgãos governamentais que não a prefeitura, neste caso), que passou a ser mobilizada pelo candidato do PDT de forma tímida na última eleição.

Uma explicação possível pode estar presente nos então ocupantes daqueles cargos no momento eleitoral. Na esfera federal, o presidente Michel Temer (PMDB) assumiu o poder após o impeachment de Dilma Rousseff (PT) ter sua fase final aprovada ao longo da campanha municipal em curso. No governo estadual, Beto Richa (PSDB) era opositor de Fruet - ambos mantiveram relação tumultuada no curso dos quatro anos de mandato.

Apesar disso, duas das três variáveis restantes apresentaram aumento significativo: uso do cargo (que se refere a todos os cargos ocupados pelo candidato em sua carreira política, incluindo os não eletivos), com 34,2\% de crescimento; e associação à administração em disputa, com 68,6\% de acréscimo. A variável postura acima da briga (considerada presente quando o candidato nem ataca, nem se defende) também foi mais registrada em 2016 em relação a 2012, mas com crescimento tímido.

Já para Greca, neste caso, nota-se que as variações no uso de estratégias típicas de mandatário foram pequenas. A variável que mais teve acréscimo foi a associação à administração em outra esfera, com 6,6\% de aumento. Tal resultado pode estar relacionado à coligação formada por Greca com o grupo político de Beto Richa (PSDB), governador do Paraná. Já a variável que mais sofreu queda foi a de postura acima da 
briga, que caiu 6,5\%. O dado indica que, em 2016, o atual prefeito de Curitiba adotou postura mais ofensiva do que em 2012.

Para continuar a verificação das duas hipóteses iniciais deste artigo passamos, então, aos dados sobre a presença das estratégias consideradas típicas de desafiante, descritos na tabela 2.

TABELA 2 - Estratégias típicas de desafiante

\begin{tabular}{|l|c|c|c|c|c|c|}
\cline { 2 - 7 } \multicolumn{1}{c|}{} & \multicolumn{3}{c|}{ FRUET } & \multicolumn{3}{c|}{ GRECA } \\
\cline { 2 - 7 } & $\mathbf{2 0 1 2}$ & $\mathbf{2 0 1 6}$ & Diferença & $\mathbf{2 0 1 2}$ & $\mathbf{2 0 1 6}$ & Diferença \\
\hline $\begin{array}{l}\text { Apelo a } \\
\text { mudanças }\end{array}$ & $6,7 \%$ & $0 \%$ & $-6,7 \%$ & $14,7 \%$ & $21 \%$ & $6,3 \%$ \\
\hline $\begin{array}{l}\text { Ofensiva quanto } \\
\text { a temas }\end{array}$ & $55,7 \%$ & $63,5 \%$ & $7,8 \%$ & $65,7 \%$ & $28 \%$ & $-37,7 \%$ \\
\hline $\begin{array}{l}\text { Ataques à } \\
\text { administração } \\
\text { em curso }\end{array}$ & $11,7 \%$ & $0 \%$ & $-11,7 \%$ & $19,6 \%$ & $4,3 \%$ & $-15,3 \%$ \\
\hline $\begin{array}{l}\text { Ataques aos } \\
\text { adversários }\end{array}$ & $5,5 \%$ & $1,2 \%$ & $-4,3 \%$ & $1 \%$ & $3,8 \%$ & $2,8 \%$ \\
\hline
\end{tabular}

FONTE: os autores, 2018.

Considerando as quatro estratégias típicas de desafiante, Fruet segue o esperado e apresenta queda na maioria das variáveis. Como já apontado na tabela 1, o político do PDT atacou menos em 2016, quando apenas 1,2\% dos segmentos trazia elementos de campanha negativa em relação aos adversários. Cabe destacar, entretanto, que a abordagem de temas de políticas públicas na campanha de Fruet cresceu em 2016, ano em que 63,5\% dos segmentos foram destinados a este fim.

Greca, por outro lado, contrariou as expectativas e apresentou queda no uso de três das cinco variáveis típicas de desafiante. A que mais chama a atenção é a ofensiva quanto a temas, que caiu 37,7\% na última eleição. O resultado indica que o candidato usou mais de dois terços de seus segmentos buscando, por exemplo, construir a sua própria imagem ou engajar o eleitor. Duas variáveis tiveram crescimento, 
incluindo o ataque a adversários, que teve aumento de 2,8\%.

Ademais, com relação à campanha negativa, cabe aqui salientar que a relativamente baixa ocorrência destas variáveis segue em consonância com resultados já encontrados na literatura brasileira (BORBA, 2015). Em um contexto de primeiro turno de eleição e, além disso, tendo em vista os constrangimentos da lei eleitoral e a possibilidade de efeito bumerangue, o esperado é justamente que o uso desse recurso não apareça de forma significativa.

Os resultados apontados até aqui, portanto, mostram que Fruet diminuiu o uso de cinco estratégias típicas de mandatário em 2016 mas aumentou a utilização de outras três, sendo duas com acréscimo significativo. Além disso, Fruet fez menos uso das estratégias de desafiante, o que nos leva a afirmar que a primeira hipótese do artigo pode ser parcialmente confirmada.

A hipótese dois, por outro lado, foi contestada diante dos resultados obtidos na análise da campanha de Greca. Além de diminuir o uso de metade das estratégias para desafiante, a campanha do candidato do PMN acabou por mobilizar mais duas das estratégias típicas de mandatário. Para compreender esta dinâmica, passamos agora a analisar o uso das já referidas estratégias nas campanhas de 2012 e 2016 levando em consideração o desempenho dos candidatos nas pesquisas de intenção de voto. Para tanto, observamos a porcentagem de segmentos de Fruet e Greca que utilizaram as estratégias típicas de mandatário e de desafiante por semana, relacionando esses dados aos resultados das pesquisas eleitorais.

A opção pela utilização dos dados por semana busca verificar se houve mudanças ao longo do processo eleitoral, especialmente levando em conta as posições dos candidatos nas pesquisas de intenção de voto. Dessa forma, com a segmentação em semanas é possível observar se há mudanças no comportamento dos candidatos a partir dos resultados das pesquisas de intenção de voto - o que não se mostra viável se observarmos os dados agregados por turno. Partimos da premissa, também presente na literatura, de que a posição dos candidatos nas pesquisas pode alterar o seu comportamento, ainda mais em períodos próximos ao pleito.

7 Os resultados foram consultados no endereço www.eleicoes.ibopeinteligencia.com.br. 
No pleito de 2012, a veiculação do HGPE compreendia o período entre os dias 21 de agosto e 04 de outubro. Nesse intervalo, foram divulgadas três pesquisas lbope ${ }^{7}$ de intenção de voto. Na primeira, no dia 24 de agosto de 2012, Fruet aparece com 21\% das intenções de voto, enquanto Greca soma 6\%. Em seguida, no dia 14 de setembro, Fruet tem queda para 16\%, enquanto o então candidato do PMDB cresce $2 \%$ na pesquisa. Por fim, no dia 02 de outubro, já perto da realização das eleições, Fruet se mantém estável enquanto Greca ganha mais um ponto percentual e chega aos 9\% das intenções de voto. Assim, a semana 1 corresponde à primeira pesquisa, enquanto a semana 4 corresponde à segunda pesquisa. Já a semana 6 corresponde à terceira e à última pesquisa realizada.

$\mathrm{Na}$ tabela 3 abaixo apresentamos o percentual de segmentos com presença das estratégias típicas de mandatário por semanas de campanha para cada candidato. As células pintadas em vermelho indicam período de queda de desempenho na pesquisa para o candidato, enquanto em azul estão as melhoras. Já as células verdes indicam a manutenção do percentual de intenção de voto na pesquisa do lbope.

TABELA 3 - Estratégias típicas de mandatário por semana em 2012

\begin{tabular}{|c|c|c|c|c|c|c|c|}
\hline & \multirow{3}{*}{$\frac{1}{0 \%}$} & \multirow{3}{*}{$\begin{array}{c}2 \\
0 \%\end{array}$} & \multirow{3}{*}{$\begin{array}{c}3 \\
0 \%\end{array}$} & \multirow{3}{*}{\begin{tabular}{|c|c|}
4 \\
$5,3 \%$
\end{tabular}} & \multirow{3}{*}{\begin{tabular}{|c|}
$\mathbf{5}$ \\
$9,7 \%$ \\
\end{tabular}} & \multirow{3}{*}{\begin{tabular}{|c|}
6 \\
$9,5 \%$ \\
\end{tabular}} \\
\hline & & & & & & & \\
\hline \multirow{2}{*}{ Uso do cargo } & Fruet & & & & & & \\
\hline & Greca & $16,7 \%$ & $20,7 \%$ & $25 \%$ & $35 \%$ & $15,8 \%$ & $31,3 \%$ \\
\hline \multirow{2}{*}{$\begin{array}{l}\text { Postura acima } \\
\text { da briga }\end{array}$} & Fruet & $90,9 \%$ & $100 \%$ & $100 \%$ & $89,5 \%$ & $83,9 \%$ & $97,6 \%$ \\
\hline & Greca & $100 \%$ & $100 \%$ & $100 \%$ & $100 \%$ & $100 \%$ & $93,8 \%$ \\
\hline \multirow{2}{*}{$\begin{array}{l}\text { Associação à } \\
\text { administração } \\
\text { em disputa }\end{array}$} & Fruet & $0 \%$ & $0 \%$ & $6,30 \%$ & $0 \%$ & $0 \%$ & $0 \%$ \\
\hline & Greca & $0 \%$ & $3,4 \%$ & $0 \%$ & $0 \%$ & $10,5 \%$ & $6,3 \%$ \\
\hline \multirow{2}{*}{$\begin{array}{l}\text { Associação à } \\
\text { administração } \\
\text { de outra esfera }\end{array}$} & Fruet & $0 \%$ & $2,3 \%$ & $6,30 \%$ & $52,6 \%$ & $12,9 \%$ & $16,7 \%$ \\
\hline & Greca & $0 \%$ & $3,4 \%$ & $16,70 \%$ & $0 \%$ & $0 \%$ & $18,8 \%$ \\
\hline \multirow{2}{*}{$\begin{array}{l}\text { Endosso de } \\
\text { lideranças } \\
\text { políticas }\end{array}$} & Fruet & $0 \%$ & $2,3 \%$ & $0 \%$ & $10,5 \%$ & $12,9 \%$ & $16,7 \%$ \\
\hline & Greca & $0 \%$ & $0 \%$ & $8,30 \%$ & $0 \%$ & $5,30 \%$ & $0 \%$ \\
\hline
\end{tabular}




\begin{tabular}{|l|l|l|l|l|l|l|c|}
\hline $\begin{array}{l}\text { Endosso de } \\
\text { lideranças da } \\
\text { sociedade civil }\end{array}$ & Fruet & $0 \%$ & $0 \%$ & $0 \%$ & $10,5 \%$ & $0 \%$ & $4,8 \%$ \\
\cline { 2 - 8 } & Greca & $0 \%$ & $0 \%$ & $0 \%$ & $0 \%$ & $0 \%$ & $6,3 \%$ \\
\hline $\begin{array}{l}\text { Endosso do } \\
\text { patrono }\end{array}$ & Fruet & $0 \%$ & $2,3 \%$ & $0 \%$ & $0 \%$ & $0 \%$ & $7,1 \%$ \\
\cline { 2 - 8 } & Greca & $0 \%$ & $0 \%$ & $0 \%$ & $0 \%$ & $5,3 \%$ & $0 \%$ \\
\hline $\begin{array}{l}\text { Menção } \\
\text { ao partido/ } \\
\text { coligação }\end{array}$ & Fruet & $0 \%$ & $0 \%$ & $0 \%$ & $21,1 \%$ & $3,2 \%$ & $4,8 \%$ \\
\cline { 2 - 8 } & Greca & $0 \%$ & $0 \%$ & $0 \%$ & $20 \%$ & $0 \%$ & $0 \%$ \\
\hline
\end{tabular}

FONTE: os autores, 2018.

Com relação a Gustavo Fruet, é possível perceber a partir dos dados da tabela que somente a variável "endosso do patrono" não sofreu alterações a partir da divulgação da segunda pesquisa eleitoral, em que o candidato apresenta queda no percentual de intenções de voto. Podemos perceber que há aumento do uso do cargo, da associação à administração em outra esfera, do endosso de lideranças - tanto políticas quanto da sociedade civil - e também da menção ao partido. Além disso, há queda na postura acima da briga, isto é, o candidato passa a atacar mais diante do resultado da pesquisa. Há também queda na associação à administração em disputa, o que pode indicar que o candidato buscou se desvincular do grupo que estava na administração municipal.

$\mathrm{Na}$ terceira pesquisa, divulgada na semana 6, Fruet se mantém estável e nas variáveis uso do cargo, associação à administração em disputa e endosso de lideranças políticas mantém a mesma tendência vista anteriormente. Já a postura acima da briga aumenta, o que indica que o candidato deixa de atacar. A associação à administração em outra esfera, o endosso de lideranças da sociedade civil e a menção ao partido diminuem. Por outro lado, cresce o endosso do patrono, o que indica que o candidato ainda busca legitimação perante o eleitorado por meio de figuras conhecidas pelo público.

Rafael Greca, por outro lado, apresentou crescimento em ambas as pesquisas eleitorais divulgadas pelo lbope no período. Apesar disso, não parece existir relação entre o uso das estratégias típicas de mandatário e as pesquisas de intenção de voto nesse caso. Observase aumento do uso do cargo e da menção ao partido na segunda pesquisa, enquanto endosso de lideranças políticas e associação à administração em outra esfera apresentam queda. Já endosso do patrono, associação à administração em disputa e postura acima da 
briga se mantém estáveis.

Na divulgação da terceira pesquisa, contudo, o comportamento se modifica, mesmo com a crescente das intenções de voto no candidato se manter. Uso do cargo, associação à administração em disputa e de outra esfera e endosso de lideranças da sociedade civil aumentam. Por outro lado, endosso do patrono e postura acima da briga diminuem, enquanto endosso de lideranças políticas se mantém relativamente estável. Tais resultados podem se relacionar ao fato de Greca ser desafiante na eleição de 2012. Por isso, cabe verificar também como se deu o comportamento dos candidatos no que se refere às estratégias desse tipo de concorrente, o que traz a tabela 4.

TABELA 4 - Estratégias típicas de desafiante por semana em 2012

\begin{tabular}{|c|c|c|c|c|c|c|c|}
\hline & \multirow{3}{*}{$\begin{array}{c}\mathbf{1} \\
0 \%\end{array}$} & \multirow{3}{*}{$\begin{array}{c}2 \\
6,8 \%\end{array}$} & \multirow{3}{*}{$\begin{array}{c}3 \\
\%\end{array}$} & \multirow{3}{*}{$\begin{array}{c}4 \\
5,3 \%\end{array}$} & \multirow{3}{*}{$\begin{array}{c}5 \\
0 \%\end{array}$} & \multirow{3}{*}{$\begin{array}{c}6 \\
16,7 \%\end{array}$} \\
\hline & & & & & & & \\
\hline Apelo a & Fruet & & & & & & \\
\hline mudanças & Greca & $0 \%$ & $27,6 \%$ & $0 \%$ & $10 \%$ & $5,3 \%$ & $25 \%$ \\
\hline \multirow{2}{*}{$\begin{array}{l}\text { Ofensiva } \\
\text { quanto a } \\
\text { temas }\end{array}$} & Fruet & $72,7 \%$ & $59,1 \%$ & $62,5 \%$ & $57,9 \%$ & $54,8 \%$ & $52,4 \%$ \\
\hline & Greca & $50 \%$ & $89,7 \%$ & $75 \%$ & $40 \%$ & $73,7 \%$ & $50 \%$ \\
\hline \multirow{2}{*}{$\begin{array}{l}\text { Ataques à } \\
\text { administração } \\
\text { em curso }\end{array}$} & Fruet & $9,1 \%$ & $2,3 \%$ & $6,3 \%$ & $15,8 \%$ & $19,4 \%$ & $16,7 \%$ \\
\hline & Greca & $0 \%$ & $24,1 \%$ & $0 \%$ & $5 \%$ & $26,3 \%$ & $43,8 \%$ \\
\hline \multirow{2}{*}{$\begin{array}{l}\text { Ataque aos } \\
\text { adversários }\end{array}$} & Fruet & $9,1 \%$ & $2,3 \%$ & $0 \%$ & $5,3 \%$ & $12,9 \%$ & $4,8 \%$ \\
\hline & Greca & $0 \%$ & $0 \%$ & $0 \%$ & $0 \%$ & $0 \%$ & $6,3 \%$ \\
\hline
\end{tabular}

FONTE: os autores, 2018.

No que diz respeito às estratégias típicas de desafiante, é possível perceber que para ambos os candidatos a tendência foi de aumento no uso da maioria dos recursos, independentemente do resultado da pesquisa. As exceções são a ofensiva quanto a temas, que teve ligeira queda no caso de Fruet, e ataque aos adversários, que diminuiu para ambos os candidatos. Considera-se, portanto, que as pesquisas eleitorais tiveram maior influência, em 2012, no caso de Fruet para as estratégias de mandatário.

Nas eleições de 2016, por sua vez, o período para campanha eleitoral 
foi reduzido. Assim, a veiculação do HGPE compreendeu o intervalo entre os dias 26 de agosto e 29 de setembro, totalizando cinco semanas de campanha. Consideramos, nesse caso, duas pesquisas eleitorais feitas pelo Ibope. Na primeira, veiculada em 23 de agosto - pouco antes do início do HGPE -, o então candidato a reeleição Gustavo Fruet aparece com 19\% das intenções de voto, enquanto Greca tem 28\%. Já na segunda, de 19 de setembro, Greca cresce significativamente, chegando aos 45\%, enquanto Fruet cai para 16\% das intenções de voto.

$\mathrm{Na}$ tabela 5 abaixo realizamos o confronto desses dados com o uso das estratégias típicas de mandatário, de modo semelhante ao realizado anteriormente. Cabe esclarecer, contudo, que três estratégias não registraram nenhuma ocorrência entre os candidatos - endosso de lideranças da sociedade civil e do patrono, e menção ao partido - e por isso não são mencionadas na tabela.

TABELA 5 - Estratégias típicas de mandatário por semana em 2016

\begin{tabular}{|c|c|c|c|c|c|c|}
\hline & \\
\hline & & 1 & 2 & 3 & 4 & 5 \\
\hline \multirow{2}{*}{ Uso do cargo } & Fruet & $60,9 \%$ & $48,1 \%$ & $27,8 \%$ & $63,9 \%$ & $12,8 \%$ \\
\hline & Greca & $44 \%$ & $30,6 \%$ & $15,8 \%$ & $0 \%$ & $16,3 \%$ \\
\hline \multirow{2}{*}{$\begin{array}{l}\text { Postura acima da } \\
\text { briga }\end{array}$} & Fruet & $95,7 \%$ & $96,3 \%$ & $100 \%$ & $100 \%$ & $100 \%$ \\
\hline & Greca & $100 \%$ & $94,4 \%$ & $94,7 \%$ & $95,5 \%$ & $81,4 \%$ \\
\hline \multirow{2}{*}{$\begin{array}{l}\text { Associação à } \\
\text { administração } \\
\text { em disputa }\end{array}$} & Fruet & $56,5 \%$ & $88,9 \%$ & $97,2 \%$ & $66,7 \%$ & $44,7 \%$ \\
\hline & Greca & $32 \%$ & $25 \%$ & $2,6 \%$ & ०\% & ०\% \\
\hline \multirow{2}{*}{$\begin{array}{l}\text { Associação à } \\
\text { administração de } \\
\text { outra esfera }\end{array}$} & Fruet & $17,4 \%$ & $0 \%$ & $0 \%$ & $0 \%$ & $0 \%$ \\
\hline & Greca & $12 \%$ & $0 \%$ & $0 \%$ & $0 \%$ & $0 \%$ \\
\hline \multirow{2}{*}{$\begin{array}{l}\text { Endosso de } \\
\text { lideranças } \\
\text { políticas }\end{array}$} & Fruet & $8,7 \%$ & $0 \%$ & $0 \%$ & $5,6 \%$ & $0 \%$ \\
\hline & Greca & $0 \%$ & ०\% & $2,6 \%$ & $0 \%$ & $0 \%$ \\
\hline
\end{tabular}

FONTE: os autores, 2018.

No caso de Fruet, é interessante notar que há crescimento do uso do

8 Disponível em: g1.globo.com/pr/parana/eleicoes/2016/noticia/2016/08/greca-lidera-disputa-para-prefeitura-de-curitiba-com-28-diz-ibope.html. 
cargo e do endosso de lideranças políticas, enquanto a postura acima da briga se mantém estável, na medida em que os ataques representam alto risco para os candidatos. Já a associação à administração em disputa cai de modo significativo, o que pode ser um reflexo das taxas de aprovação do governo do candidato do PDT. Pouco antes do início do horário eleitoral, $42 \%$ dos eleitores consideravam sua gestão regular e $37 \%$ ruim ou péssima ${ }^{8}$. Dessa forma, associar-se à gestão da prefeitura poderia não ser interessante para o candidato.

Para Greca, por outro lado, destaca-se a diminuição gradual da associação da imagem do candidato à prefeitura, além da queda no uso do cargo. No caso da postura acima da briga, há crescente diminuição ao longo do período, o que indica que o candidato passa a atacar de forma mais significativa à medida que a eleição se aproxima. Os dados para as estratégias típicas de desafiante são apresentados na tabela 6.

TABELA 6 - Estratégias típicas de desafiante por semana em 2016

\begin{tabular}{|c|c|c|c|c|c|c|}
\hline & & & & & \\
\hline & & 1 & 2 & 3 & 4 & 5 \\
\hline \multirow{2}{*}{$\begin{array}{l}\text { Apelo a } \\
\text { mudanças }\end{array}$} & Fruet & ०\% & ०\% & ०\% & ०\% & $0 \%$ \\
\hline & Greca & $28 \%$ & $38,9 \%$ & $23,7 \%$ & 2,3\% & $18,6 \%$ \\
\hline \multirow{2}{*}{$\begin{array}{l}\text { Ofensiva quanto } \\
\text { a temas }\end{array}$} & Fruet & $60,9 \%$ & $81,5 \%$ & $72,2 \%$ & $44,4 \%$ & $31,9 \%$ \\
\hline & Greca & $20 \%$ & $41,7 \%$ & $28,9 \%$ & $25 \%$ & $23,3 \%$ \\
\hline \multirow{2}{*}{$\begin{array}{l}\text { Ataques à } \\
\text { administração } \\
\text { em curso }\end{array}$} & Fruet & $0 \%$ & $0 \%$ & $0 \%$ & $0 \%$ & $0 \%$ \\
\hline & Greca & $0 \%$ & $2,8 \%$ & $2,6 \%$ & $4,5 \%$ & $9,3 \%$ \\
\hline \multirow{2}{*}{$\begin{array}{l}\text { Ataque aos } \\
\text { adversários }\end{array}$} & Fruet & $4,3 \%$ & $3,7 \%$ & $0 \%$ & $0 \%$ & $0 \%$ \\
\hline & Greca & $0 \%$ & ०\% & $2,6 \%$ & $0 \%$ & $14 \%$ \\
\hline
\end{tabular}

FONTE: os autores, 2018.

Já no que diz respeito às estratégias típicas de desafiante, é possível perceber que Fruet se mantém relativamente estável mesmo com a divulgação da pesquisa. O que chama atenção é que há queda significativa na ofensiva quanto a temas, o que indica que, a partir dos 
dados desfavoráveis, o candidato passou a tratar menos de políticas públicas. Já no caso de Greca, há queda no apelo a mudanças e na ofensiva quanto a temas, porém aumento dos ataques à administração em curso. Considerando que Fruet seria seu adversário direto, o candidato do PMN passa a atacar sua gestão de forma mais frequente no HGPE.

Diante dos resultados que contrariam nossas hipóteses iniciais, buscamos aprofundar a análise do HGPE de ambos os candidatos a partir da análise do conteúdo de seus programas. Ademais, na seção a seguir realizamos o teste de nossa última hipótese.

\section{O conteúdo dos segmentos}

Para saber mais sobre o uso do HGPE por Greca e Fruet, objetivo principal desse artigo, serão apresentados dados do segundo grupo de variáveis do livro de códigos utilizado pelo CPOP: o que se refere ao conteúdo dos segmentos. Assim, a comparação entre os dois pretendentes ao cargo em pleitos diferentes poderá restar melhor caracterizada. Na tabela 3 abaixo são descritos os resultados quanto ao tipo de apelo mobilizado pelos candidatos.

TABELA 7 - Apelo

\begin{tabular}{|l|c|c|c|c|c|c|}
\cline { 2 - 7 } \multicolumn{1}{c|}{} & \multicolumn{3}{c|}{ FRUET } & \multicolumn{3}{c|}{ GRECA } \\
\cline { 2 - 7 } & 2012 & 2016 & Diferença & 2012 & 2016 & Diferença \\
\hline Pragmático & $41,7 \%$ & $48,5 \%$ & $6,8 \%$ & $44,1 \%$ & $22,6 \%$ & $-21,5 \%$ \\
\hline Ideológico & $1,8 \%$ & $0,0 \%$ & $-1,8 \%$ & $2,0 \%$ & $0,0 \%$ & $-2,0 \%$ \\
\hline Político & $5,5 \%$ & $0,6 \%$ & $-4,9 \%$ & $4,9 \%$ & $1,1 \%$ & $-3,8 \%$ \\
\hline Emocional & $50,3 \%$ & $49,1 \%$ & $-1,2 \%$ & $47,1 \%$ & $75,8 \%$ & $28,7 \%$ \\
\hline Documental & $0,6 \%$ & $1,8 \%$ & $1,2 \%$ & $2,0 \%$ & $0,5 \%$ & $-1,5 \%$ \\
\hline
\end{tabular}

FONTE: os autores, 2018.

Como mostra a tabela, Fruet apresentou poucas mudanças de uma eleição para outra. Os segmentos, assim, se dividiram entre o apelo 
emocional e o pragmático (relacionado ao debate de políticas públicas) em ambas as campanhas. Na segunda eleição, porém, a diferença entre os dois diminuiu com o aumento do uso do apelo pragmático.

Greca seguiu o caminho contrário - já indicado pela queda na abordagem de políticas públicas, como apontado na seção anterior. O candidato teve acréscimo de quase $30 \%$ no uso do apelo emocional, o qual dominou mais de dois terços dos seus segmentos. O apelo pragmático, por outro lado, sofreu significativa queda entre um pleito e outro. As demais categorias também apresentaram queda, porém de forma mais tímida.

Da mesma maneira, a retórica utilizada pelo candidato do PMN nos seus segmentos passou a ser de sedução em aproximadamente $70 \%$ das unidades de análise (tabela 4). Por outro lado, a retórica de proposição sofreu a queda mais significativa - caindo mais de 10\% entre uma eleição e outra. O uso da crítica e a mobilização de valores da política ou da sociedade também sofreram queda para o HGPE do candidato do PMN.

Mais uma vez, ao contrário de Greca, Fruet aumentou o uso da retórica de proposição, aproximando-a do recurso de sedução na última eleição. De maneira similar ao adversário, contudo, as categorias de crítica e valores sofreram queda na propaganda do candidato do PDT, enquanto a de ameaça não apareceu em 2016.

TABELA 8 - Retórica

\begin{tabular}{|l|c|c|c|c|c|c|}
\cline { 2 - 7 } \multicolumn{1}{c|}{} & \multicolumn{3}{c|}{ FRUET } & \multicolumn{3}{c|}{ GRECA } \\
\cline { 2 - 7 } & 2012 & 2016 & Diferença & 2012 & 2016 & Diferença \\
\hline Sedução & $44,8 \%$ & $47,9 \%$ & $3,1 \%$ & $49,0 \%$ & $70,4 \%$ & $21,4 \%$ \\
\hline Proposição & $33,7 \%$ & $47,3 \%$ & $13,6 \%$ & $31,4 \%$ & $19,9 \%$ & $-11,5 \%$ \\
\hline Crítica & $10,4 \%$ & $1,8 \%$ & $-8,6 \%$ & $14,7 \%$ & $8,1 \%$ & $-6,6 \%$ \\
\hline Valores & $9,8 \%$ & $3,0 \%$ & $-6,8 \%$ & $4,9 \%$ & $1,6 \%$ & $-3,3 \%$ \\
\hline Ameaça & $1,2 \%$ & $0,0 \%$ & $-1,2 \%$ & $0,0 \%$ & $0,0 \%$ & $0,0 \%$ \\
\hline
\end{tabular}

FONTE: os autores, 2018. 
Completando essa parte da análise, a tabela 9 traz o tipo de linguagem usada pelos candidatos em seus segmentos. Os dois seguiram padrão semelhante, porém Greca apresentou, mais uma vez, diferenças mais acentuadas. A linguagem didática foi menos usada pelos candidatos em 2016, ao passo que a panfletária apareceu em um percentual maior de segmentos. O crescimento do candidato do PMN no uso desse último recurso, entretanto, foi bastante significativo e foi maior que o dobro do crescimento de Fruet. A diferença entre os candidatos também aparece no uso da linguagem informativa, que cresceu para o pedetista e diminuiu para Greca.

TABELA 9 - Linguagem

\begin{tabular}{|l|c|c|c|c|c|c|}
\cline { 2 - 7 } \multicolumn{1}{c|}{} & \multicolumn{3}{c|}{ FRUET } & \multicolumn{3}{c|}{ GRECA } \\
\cline { 2 - 7 } & 2012 & 2016 & Diferença & 2012 & 2016 & Diferença \\
\hline Didática & $23,3 \%$ & $5,9 \%$ & $-17,4 \%$ & $26,5 \%$ & $4,3 \%$ & $-22,2 \%$ \\
\hline Informativa & $50,9 \%$ & $57,4 \%$ & $6,5 \%$ & $45,1 \%$ & $40,9 \%$ & $-4,2 \%$ \\
\hline Panfletária & $25,8 \%$ & $36,7 \%$ & $10,9 \%$ & $28,4 \%$ & $54,8 \%$ & $26,4 \%$ \\
\hline
\end{tabular}

FONTE: os autores, 2018.

Sabendo como os candidatos apresentaram as informações em seus programas, passamos agora a observar do que eles trataram no HGPE. Testamos, assim, a última hipótese do artigo, que supõe que o tema econômico apareceria mais em 2016 em relação a 2012 por conta de variáveis contextuais. Para alcançar os resultados, mobilizamos mais uma das variáveis do segundo grupo do livro de códigos, que trata do conteúdo dos segmentos. Nela o codificador deve identificar qual dos temas listados foi tratado na unidade de análise, com categorias que se referem a políticas públicas e outras que tratam da construção da imagem do candidato e do partido, por exemplo, e também da chamada metacampanha - debates, pesquisas eleitorais, pedagogia do voto, etc.

Como já havia sido exposto nas variáveis típicas de desafiante, Fruet tratou mais de políticas públicas em 2016 do que em 2012, com 63,5\% dos segmentos destinados a este fim. No gráfico 1, a seguir, aparecem quais foram os temas tratados em ambas as eleições pelo candidato do PDT. Dois temas lideraram nas duas campanhas, trocando de posições 
entre si em cada um dos pleitos: saúde e educação. Além disso, desenvolvimento urbano, transporte, bem estar social e infraestrutura apresentaram aumento de um pleito para outro.

Três categorias apareceram somente em 2016 - incluindo economia, tema da nossa hipótese. A presença deste tema, entretanto, rog̊ io significativa: somente $1,2 \%$ dos segmentos foram diestinadios à discus são sobre temas econômicos. Os temas mulher e criança, por oert o dí desapareceram no 'iGPE de Fruei de uma eieição para outra. Um d d do que chama a atenção, por fim, é a diminuição da abordagem de vá as políticas púlolicas en unn mesmo segmento - o chamado cardá io $\mathrm{O}$ dado pode indicar que Fruet tratou os temas com mais

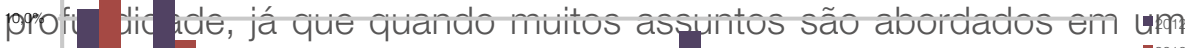

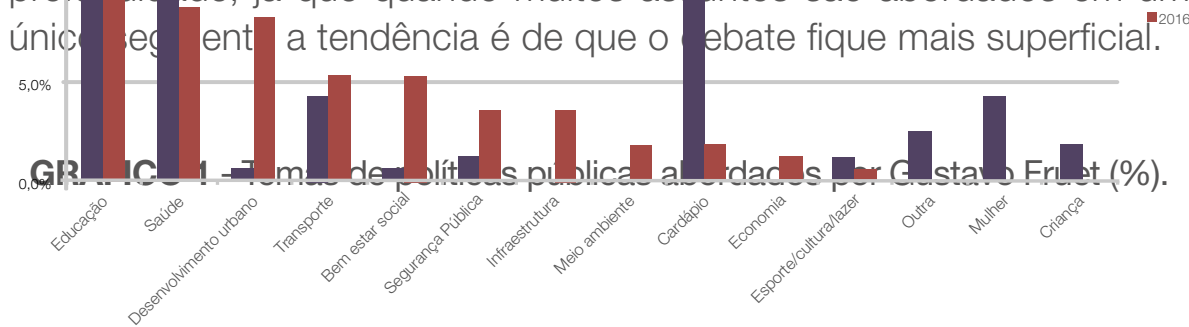

FONTE: Os autores, 2018

Seguindo na direção oposta, Greca diminuiu o debate sobre políticas públicas em seu horário eleitoral, restringindo a discussão a $28 \%$ dos seus segmentos em 2016. A diminuição é visível no gráfico 2, em que muitos dos temas aparecem somente em 2012. Saúde, que em 2012 havia liderado quando o assunto era política pública (com

9 Mais em: http://www.gazetadopovo.com.br/blogs/caixa-zero/greca-diz-que-vomitou-com-cheiro-de-pobre. 
18,6\% de aparições), caiu para 7\% quatro anos depois. O debate sobre transporte, outro assunto que havia sido abordado de forma significativa por Greca, sofreu queda de mais de 10\% e ficou restrito a 1,6\% dos segmentos.

Desta forma, entre as categorias que tinham destaque em 2012, a uninica que não sofreu queda significativa foi cardápio - justamente a que, ${ }^{18.0 \%} 0^{\circ}$ o dit acima, tende a trazer o debate de politicas públicas de torma ifialis sup rficial. Ailguns temas, entretanto, foram abordadios somente efr̊ 2016 criança, segurança púbilica e moradores de rua, sendo este

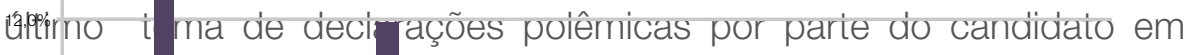

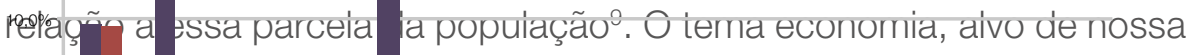

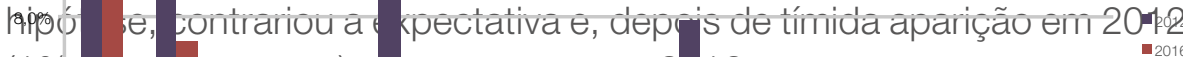

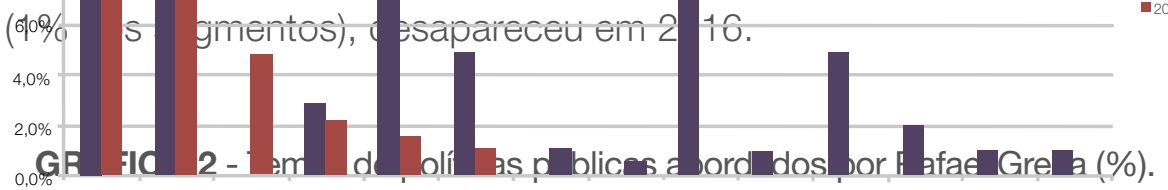

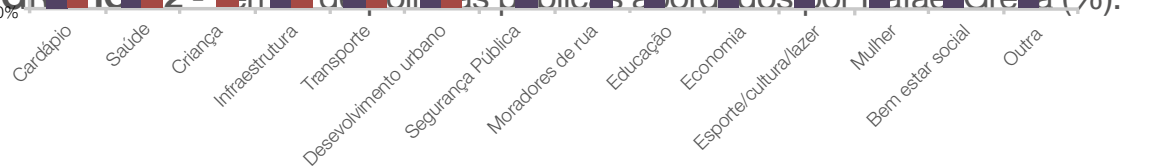

Com esses resultados, portanto, concluímos que a terceira hipótese deste artigo também não foi confirmada. O tema economia ficou muito atrás dos demais no debate do HGPE de Fruet e, no caso de Greca, nem chegou a ser pauta nos segmentos. Tendo sido realizados os testes empíricos propostos no início do artigo, passamos então às conclusões do trabalho. 


\section{Considerações Finais}

Os achados desse artigo abrem caminho para algumas questões que necessitam ser melhor exploradas com fundamentos provenientes de outras searas que as variáveis aqui mobilizadas não são capazes de responder. Em relação à primeira hipótese, ainda que não tenha utilizado de maneira uniforme todas as estratégias de mandatários listadas, Fruet se valeu de algumas estratégias bem específicas para aqueles que buscam a reeleição. $O$ fato de não ter conseguido chegar até mesmo ao segundo turno, no entanto, pode estar relacionado a outros fatores que podem ter se repetido em outras capitais (como em São Paulo). Isso indica que precisa ser levado em consideração um fenômeno de abrangência nacional de prefeitos que buscavam a reeleição nesse ano.

O uso que Rafael Greca fez do HGPE, especialmente em 2016, também chama a atenção por contrariar as expectativas baseadas na literatura. Mesmo sendo desafiante, o atual prefeito de Curitiba não apostou nessas estratégias e, o que mais se destaca, não falou sobre políticas públicas de forma significativa. Apesar disso, sua campanha, com forte apelo emocional e com uma discussão superficial de temas de interesse público (já que o que predominou foi o chamado cardápio), obteve sucesso e garantiu o êxito do candidato. Não há, aqui, o estabelecimento de uma relação de causa e efeito entre propaganda e sucesso eleitoral no pleito. Considera-se, contudo, a importância do HGPE e que sua configuração afeta em alguma medida as chances dos candidatos.

Por fim, como a terceira hipótese não foi confirmada, há indícios de que a discussão econômica não foi relevante na disputa municipal, ainda que seja um assunto nacionalmente debatido e com impacto direto no cotidiano dos cidadãos. $O$ fato de assuntos mais locais terem predominado pode indicar que discussões mais amplas têm dificuldade de encontrar ressonância nos pleitos para a prefeitura.

Os dados disponíveis são inúmeros e podem permitir o estabelecimento de outras hipóteses a serem testadas que não foram apresentadas nesse artigo. Pesquisas futuras podem buscar variáveis explicativas que forneçam uma visão mais ampla da discussão, de modo a encontrar relações que possam ser generalizadas e que expliquem os comportamentos de candidatos a cargos majoritários na propaganda eleitoral. 


\section{Referências}

ALBUQUERQUE, A. Aqui você vê a verdade na tevê: a propaganda política na televisão. Niterói: Universidade Federal Fluminense, 1999.

ALBUQUERQUE, A.; DIAS, M. R. Propaganda Política e Construção da Imagem Partidária no Brasil. Civitas, vol. 2, n² 2, p.309-326, 2002a.

BAUER, M. Análise de conteúdo clássica: uma revisão. In: BAUER, Martin W.; GASKELL, George (Org.). Pesquisa qualitativa com texto, imagem e som: um manual prático. Petrópolis: Vozes, 2002. p. 189-217.

BORBA, F. Propaganda negativa nas eleições presidenciais brasileiras. Opinião Pública, Campinas, v. 21, n.2, agosto, p. 268-295. 2015

CERVI, E; MASSUCHIN, M. HGPE e formação da opinião pública no Brasil: Análise das estratégias dos principais candidatos à presidência da república em 2010. IV Congresso Latino Americano de Opinião Pública da WAPOR. Belo Horizonte - MG, 2011.

FIGUEIREDO, M.; et al. Estratégias de persuasão eleitoral: uma proposta metodológica para o estudo da propaganda eleitoral. Opinião Pública, Campinas, v. 4, n. 3, novembro, p. 182-203. 1997.

MASSUCHIN, M. et al. A construção da campanha eleitoral majoritária no HGPE. Política \& Sociedade, Florianópolis, v. 15, n. 32, 2016.

PANKE, L.; CERVI, E. Análise da comunicação eleitoral: uma proposta metodológica para os estudos do HGPE. Contemporânea - Comunicação e Cultura, Salvador, v. 9, n. 3, p. 390-404. 2011.

; TESSEROLI, R. Horário Gratuito de Propaganda Eleitoral: características e aceitação dos eleitores. Comunicação \& Sociedade (Online), v. 38, p. 103-127, 2016.

TESSEROLI, R; PANKE, L.. Quando a voz do eleitor pouco ecoa para os candidatos: estudo de caso do HGPE em Curitiba 2012. Revista Eletrônica de Ciência Política - recp, v. 6, p. 303322, 2015. 


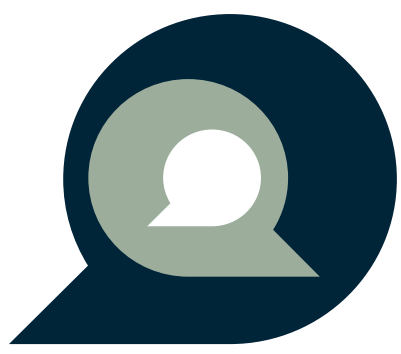

